\title{
Predicting the establishment of Diaphorina citri and Tamarixia radiata on Citrus $x$ aurantiifolia orchards based on the plant- psyllid-parasitoid interaction on Murraya paniculata
}

Dorys T. Chirinos ${ }^{1 *} \mathbb{0}$, Italo M. Cuadros ${ }^{1}$, Junior Velez ${ }^{1}$, Rossana Castro ${ }^{1}$, Ginger Sornoza ${ }^{1}$ and Takumasa Kondo ${ }^{2}$

\begin{abstract}
Background: The insect vector of Huanglongbing, Diaphorina citri Kuwayama, 1908 (Hemiptera: Lividae) was detected in Ecuador in 2013 and its main parasitoid Tamarixia radiata (Waterston, 1922) (Hymenoptera: Eulophidae) was reported for the first time in 2017. In the citrus production region of Manabí province, Ecuador, D. citri and T. radiata were reported for the first time on Murraya paniculata L. in 2016 and 2018, respectively. D. citri was first found infesting Citrus x aurantiifolia (Christm.) Swingle in Manabí province at the end of 2018. The present study was conducted between August 2018 and May 2021 to: (1) monitor D. citri populations on M. paniculata and C.x aurantiifolia and determine the parasitism rates of T. radiata on D. citri nymphs on both host plants, (2) establish the occurrence of T. radiata parasitizing D. citri on C.x aurantiifolia, and (3) calculate a predictive model for estimating the number of parasitized nymphs on a planting lot of $M$. paniculata and a C. aurantiifolia orchard.
\end{abstract}

Results: Diaphorina citri populations on M. paniculata decreased from 11 nymphs (2018-2019) to approximately 2 nymphs per flush (2020). This was associated with a natural increase in parasitism rates of T. radiata from $20 \%$ (2018) to $96 \%$ in 2020. The regression equation $(Y=2.049 \mathrm{Ln}(x)+5.88)$ was able to estimate the number of parasitized $D$. citri nymphs based on parasitism on M. paniculata $\left(R^{2}\right.$ : 0.8315). Tamarixia radiata was first detected on C.x aurantiifolia in July 2020. Populations of D. citri reached 55 nymphs per flush (no parasitism) and subsequently decreased to the minimum level of 14 nymphs per flush (parasitism rates of up to 31\%). The model allowed estimating the number of parasitized nymphs by T. radiata on M. paniculata and C. x aurantifolia, with a maximum deviation of approximately 2 nymphs.

Conclusions: Based on the colonization and establishment of the psyllid-parasitoid interaction on M. paniculata, it is estimated that approximately by the end of 2022, populations of D. citri on C.x aurantiifolia would decline due to the highest percentages of parasitism by T. radiata. High parasitism rates may indicate the potential of T. radiata in conservation biological control and integrated pest management programs.

Keywords: Diaphorina citri, Parasitism, Tamarixia radiata, Pest management

\footnotetext{
${ }^{*}$ Correspondence: dorys.chirinos@utm.edu.ec

1 Present Address: Facultad de Ingeniería Agronómica, Universidad

Técnica de Manabí, Portoviejo, Province of Manabí, Ecuador
}

Full list of author information is available at the end of the article

\section{Background}

In Ecuador, citrus agriculture represents an important agricultural activity, which occurs mainly in the continental zone. Citrus are commercially grown in six of 
the 24 provinces of Ecuador, both in the Pacific coastal region and in the highlands of the country (CañarteBermudez and Navarrete-Cedeño 2019). Approximately 29,721 ha of key limes, oranges, mandarins, among other citrus species are harvested in Ecuador, with an annual production of 17,544 tons (FAOSTAT 2019). One of the potential threats to the Ecuadorian citrus industry is Huanglongbing, considered the most destructive disease of citrus worldwide, caused by the bacteria Candidatus Liberibacter spp. that obstruct the phloem and can cause the eventual death of the plant (Bové 2006).

Although this disease has not yet been reported in Ecuador, in 2013, its known insect vector in the Americas, the Asian citrus psyllid, Diaphorina citri Kuwayama (Hemiptera, Liviidae) was detected in the coastal province of Guayas on both, Citrus spp. (Rutaceae) as well as on the ornamental plant host, orange jasmine, Murraya paniculata (L.) Jack (Rutaceae) (Cornejo and Chica 2014). From there, it spread to different citrus regions on Ecuador (Cuadros et al. 2020). After the detection of D. citri, its parasitoid, Tamarixia radiata (Waterston) (Hymenoptera: Eulophidae) was reported in the province of Guayas, following the same initial dispersal of its insect host (Portalanza et al. 2017). Subsequently, $T$. radiata was reported in other provinces of Ecuador, in the coast (Cuadros et al. 2020) and the highlands (Erraez et al. 2020).

Manabí constitutes one of the main citrus provinces of the coast where $D$. citri was observed for the first time on M. paniculata shrubs in Portoviejo 2016 (Navarrete et al. 2016). In 2018, T. radiata was found parasitizing D. citri on M. paniculata and by the end of that same year, $D$. citri began to infest key lime trees (Cuadros et al. 2020).

Diaphorina citri has a wide host range that includes 25 genera within the family Rutaceae (Halbert and Manjunath 2004). The preference of D. citri for M. paniculata over other citrus species was reported both in early observations (Aubert 1987) and in later studies (Teck et al. 2011), which probably explains that its colonization in Manabí occurred first on M. paniculata before colonizing Citrus $x$ aurantiifolia (Christm,) Swingle. Then, starting from the establishment of the plant-psyllidparasitoid interaction on $M$. paniculata in the studied area the complete establishment of the same interaction on citrus that began by the end of 2018 was predicted. .

Mathematical models have been proposed to explain psyllid-parasitoid interactions (Miksanek and Heimpel 2019). Likewise, several studies have been conducted on the population dynamics of $D$. citri resulting from interactions with density-dependent and density-independent processes (Milosavljević et al. 2021). This study aimed to explain the importance of parasitism by $T$. radiata on
D. citri, as well as the colonization and establishment of this psyllid-parasitoid interaction on M. paniculata and C. $\mathrm{x}$ aurantiifolia (Rutaceae) in the province of Manabí, Ecuador.

\section{Methods}

The study was carried out during the period August 2018-May 2021 on the host plants, orange jasmine, Murraya paniculata and key lime, Citrus $x$ aurantiffolia. In Ecuador, M. paniculata, a shrub planted as an ornamental plant, is commonly used as hedges in parks, commercial establishments and in house gardens in urban areas. One hundred and fifty plants of $M$. paniculata were planted in the Portoviejo city (Coordinates: $01^{\circ} 03^{\prime} 17^{\prime \prime} S$, $80^{\circ} 27^{\prime} 16^{\prime \prime} \mathrm{W}, 53 \mathrm{~m}$ a.s.l.), which were sampled weekly from August 2018 to December of 2020 when the parasitism reached more than $90 \%$. At the same time, a survey began at a key lime, $C$. $\mathrm{x}$ aurantiifolia orchard in an area of 2 ha, consisted of 200 4-year-old trees, located in the town of Mejía, via Crucita, Portoviejo $\left(00^{\circ} 59^{\prime} 22.4^{\prime \prime} \mathrm{S}\right.$ $80^{\circ} 27^{\prime} 57.1^{\prime \prime} \mathrm{W}, 53 \mathrm{~m}$ a.s.l.). The distance between the key lime orchards to the planting lot of orange jasmine was about $8 \mathrm{~km}$. The life zone corresponds to a tropical dry forest. Precipitation data $(\mathrm{mm})$ obtained from the National Institute of Meteorology and Hydrology of Ecuador are included.

Forty flushes (young shoots), each $10 \mathrm{~cm}$ long, were randomly sampled within the lots established for each of the host plant. These flushes were placed in plastic bags and transported to the Entomology Laboratory, Faculty of Agronomic Engineering, Technical University of Manabí. The number of non-parasitized nymphs of $D$. citri and the number of nymphs parasitized by $T$. radiata were counted. Parasitized nymphs were initially identified based on their dark brown coloration. These nymphs were placed in a Petri dish and dissected to confirm the presence of parasitoid larvae or pupae. Counts were performed, using a Carl-Zeiss ${ }^{\circledR}$ stereoscope (magnification: $10-40 \times)$.

The percentage of parasitism was calculated as follows:

$$
\frac{\text { No. of parasitized nymphs }}{\text { No. of nymphs(parasitized + non - parasitized })} \times 100
$$

\section{Data analysis}

For each of the host plants, i.e., C. $x$ aurantiifolia and $M$. paniculata, the number of non-parasitized $D$. citri nymphs, number of parasitized $D$. citri nymphs per week were averaged. Monthly averages of $D$. citri nymphs and rainfall were plotted, including a correlation analysis between both variables $(P<0.05)$. A correlation analysis was carried out between the non-parasitized $D$. citri nymphs $(X)$ and the parasitized $D$. citri nymphs $(Y)$ 
$(P<0.01)$ observed on $M$. paniculata. From these observations, an equation was subsequently obtained to estimate the number of parasitized $D$. citri nymphs $(P<0.01)$. With the calculated equation, the parasitized nymphs on both host plants were estimated.

\section{Results}

\section{Rainfall}

The plant-psyllid-parasitoid interaction was analysed to plot the population dynamics in relation to rainfall. In the province of Manabí, each year the rainy period begins approximately from January until April (Fig. 1). The torrential rains that occur in the region are associated with the decrease in population densities of $D$. citri. Thus, when rainfall ranged between 140 and $280 \mathrm{~mm}$, the populations were practically nil (Fig. 1). However, as rainfall decreases, the rutaceous plants start to produce young shoots, which are ideal for the development of $D$. citri nymphs, resulting in a population increase. This is corroborated by the highly significant inverse correlation between populations of $D$. citri and rainfall, on M. paniculata $(r:-0.5202, P<0.05)$ and on $C$. $x$ aurantiifolia $(r$ : $-0.5215, P<0.05)$.

\section{Host plant-Diaphorina citri-Tamarixia radiata interactions Orange jasmine, Murraya paniculata}

The populations of $D$. citri nymphs and $T$. radiata parasitism rates varied from the first year of evaluations
(Fig. 2a). From August to December 2018, the population densities of $D$. citri ranged 3-9 nymphs per flush (average: $4.9 \pm 0.5$ ), while the natural parasitism rate increased from 20 to $80 \%$ (average: $38 \pm 4.2$ ). In 2019 , the number of $D$. citri nymphs per flush increased from June and reached the maximum peak between August and October (range 9-11 nymphs per flush) (average: $3.7 \pm 0.5$ ). Parasitism rates ranged from 12 to $82 \%$ (2018-2019) (average: $37.2 \pm 3.2$ ), with the highest parasitism rates associated with low population densities of $D$. citri. In 2020, D. citri populations fell to their lowest values (range 0.2-2.3 nymphs) (average: $0.9 \pm 0.1$ ) coupled with higher rates of parasitism (57-96\%) (average: $81.9 \pm 1.8$ ).

The calculated logarithmic regression model showed a high and significant percentage of determination $\left(R^{2}\right.$ : $0.8315, P<0.01)$ for estimating the parasitism rates (Fig. 3a). The residual analysis showed that the equation could have a maximum deviation of approximately 2 nymphs ( $4 \%$ of the cases) (Fig. 3b). The estimated number of parasitized $D$. citri nymphs were plotted together with the non-parasitized $D$. citri nymphs and observed parasitized nymphs (Fig. 4a). It was observed that when there was a greater number of parasitized nymphs, there were fewer non-parasitized nymphs and vice versa, indicating an inverse association $(r:-0.8064$, $P<0.01)$. Likewise, the close relationship between the observed parasitized $D$. citri nymphs and the estimated parasitized $D$. citri nymphs had the greatest variation in

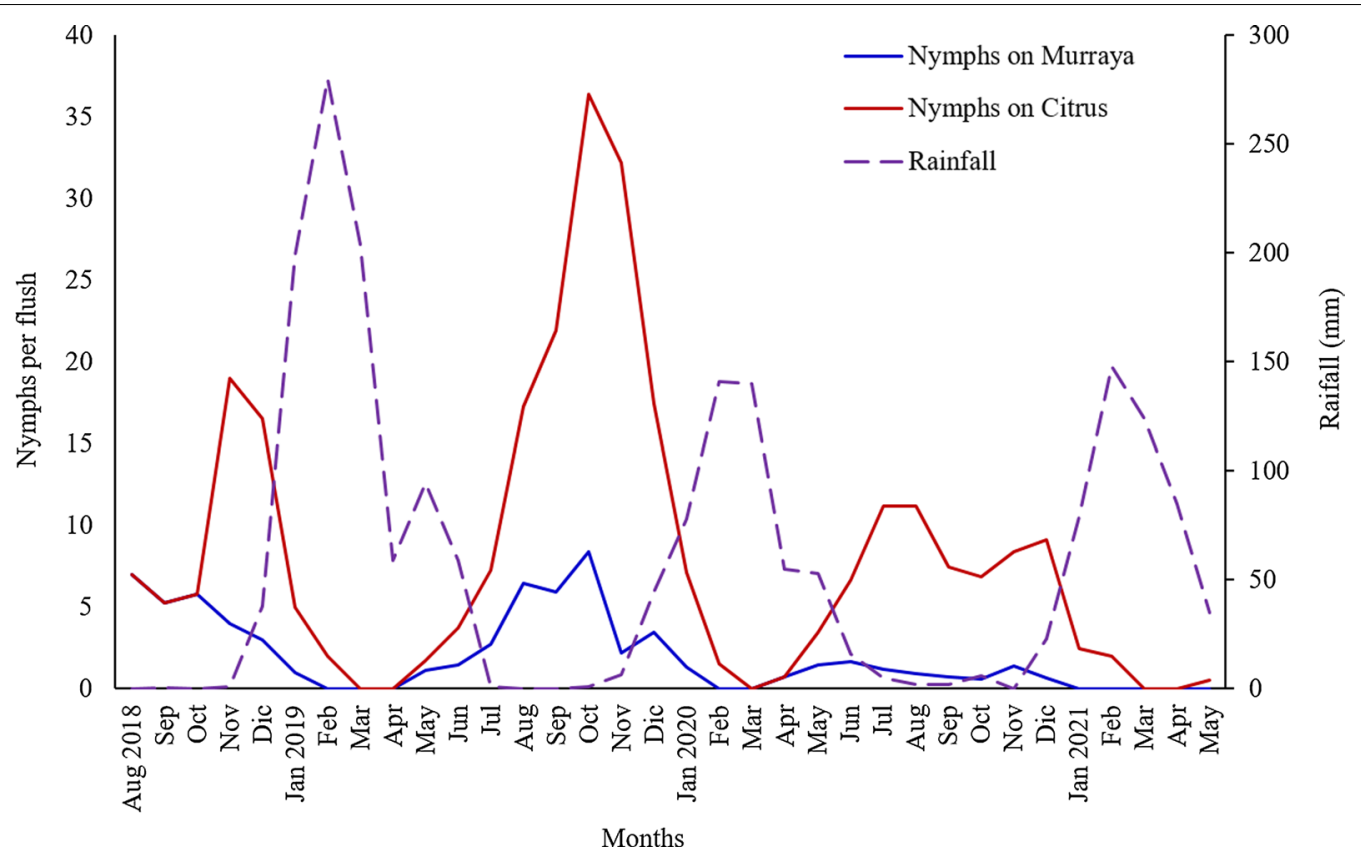

Fig. 1 Fluctuation of Diaphorina citri nymphs on both host plants and rainfall. Period August 2018-May 2021 


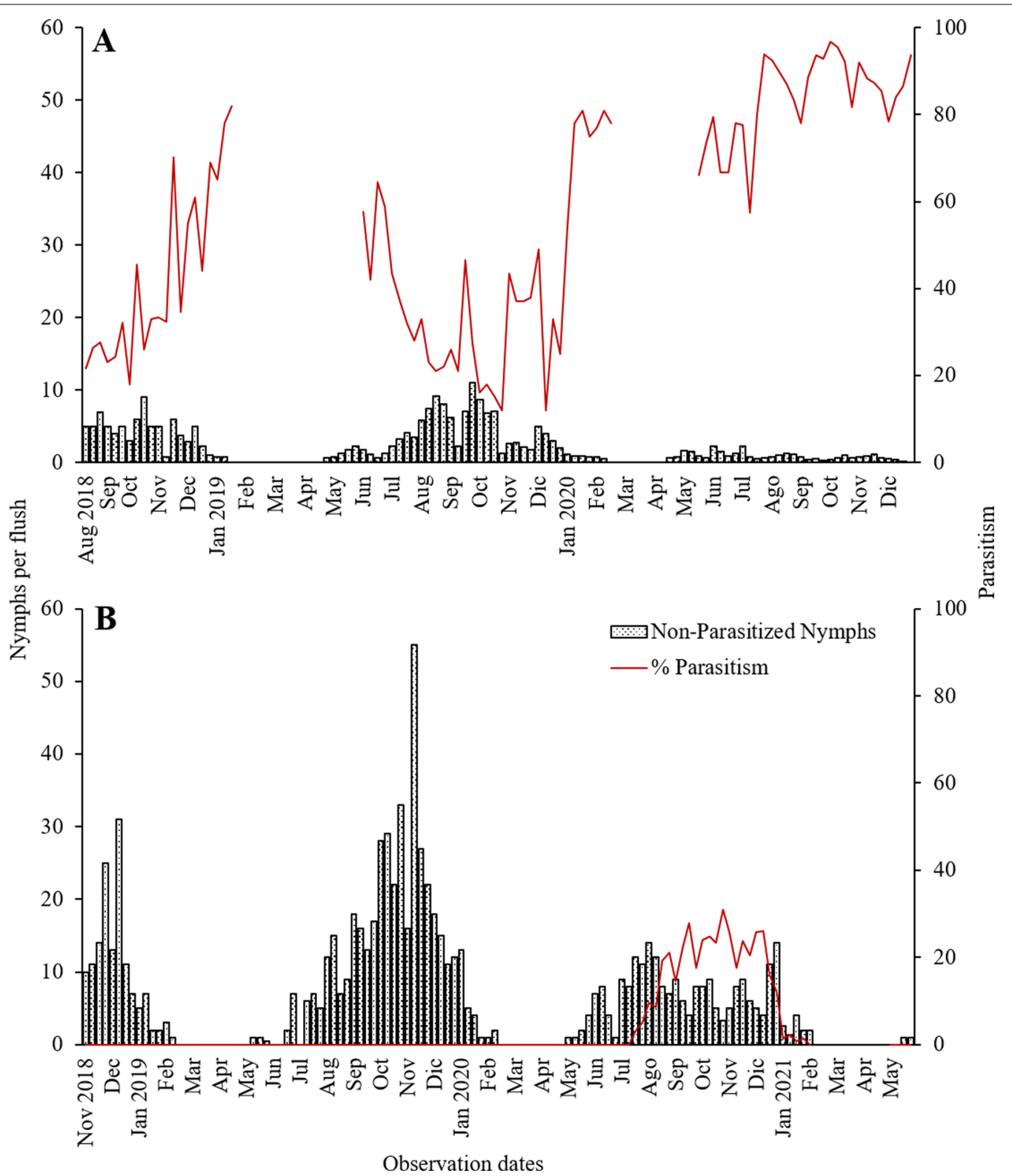

Fig. 2 Population fluctuation of non-parasitized nymphs of Diaphorina citri and the percentage of parasitism by Tamarixia radiata. a Murraya paniculata, b Citrus x aurantiifolia. Period August 2018-May 2021

the first observations (1-20) and stabilized in posterior observations (Fig. 4a).

\section{Key lime, Citrus $x$ aurantiifolia}

In 2018, when D. citri was detected on C. x aurantiifolia, populations increased with maximum peaks of 25-31 D. citri nymphs per flush (Fig. 2b) (average: $15.3 \pm 2.9$ ). However, in 2019, after the rainy season, the highest levels of 55 D. citri nymphs per flush were recorded (Fig. 5a) (average: $12.1 \pm 2.0$ ). When $D$. citri nymphs' parasitized by $T$. radiata were first detected (Fig. 5b) in July 2020, the parasitism rates were very low (3\%, Fig. $2 \mathrm{~b})$ and by the end of October 2020, it reached the maximum parasitism rates of $30 \%$ (average: $8.7 \pm 1.8$ ). Although during this period the populations continued to be high (maximum of 14 nymphs per flush), these were much lower than those reached in previous years, especially in 2019 when parasitism with $T$. radiata was absent (average: $6.5 \pm 0.6$ ).

Number of non-parasitized D. citri nymphs, the observed parasitized $D$. citri nymphs and the estimated 

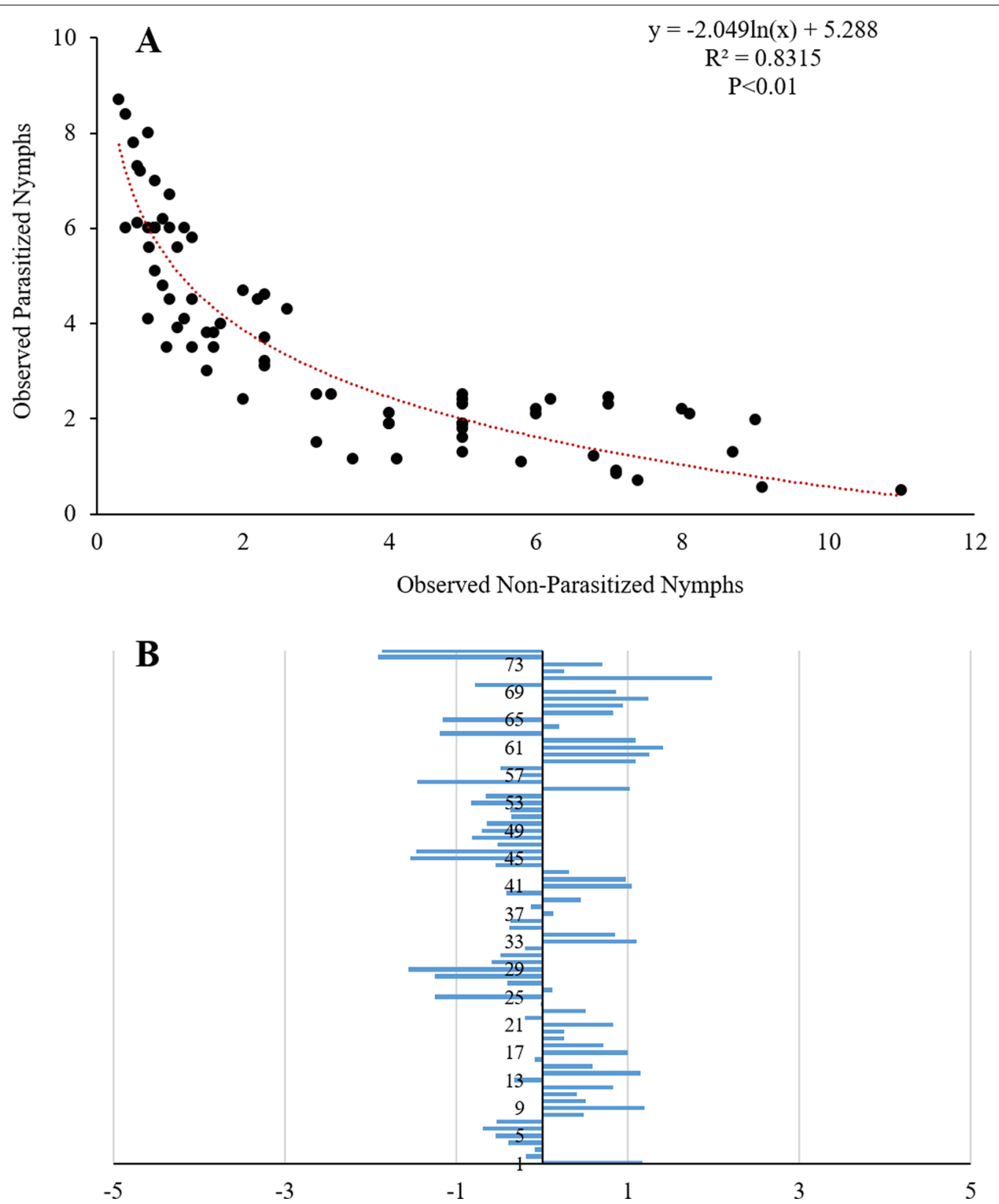

Fig. 3 a Regression analysis between parasitized and non-parasitized nymphs of Diaphorina citri observed in the study on Murraya paniculata. $\mathbf{b}$ Residuals in the nymph estimation

parasitized D. citri nymphs on $C$. x aurantiifolia are shown in Fig. 4b. The variations found between the observed number of parasitized $D$. citri nymphs and the estimated number of parasitized $D$. citri nymphs in the 22 observations were similar to those found on M. paniculata in the 2nd half of 2018 . The residue analysis between the observed number of parasitized $D$. citri nymphs and the estimated number of parasitized nymphs on key lime showed the same deviation trends (2 nymphs per flush) as the residue analysis estimated in M. paniculata (Fig. 3b).

\section{Discussion}

The highly significant inverse correlation between the numbers of $D$. citri nymphs versus rainfall indicated that this abiotic factor regulates the population densities of 


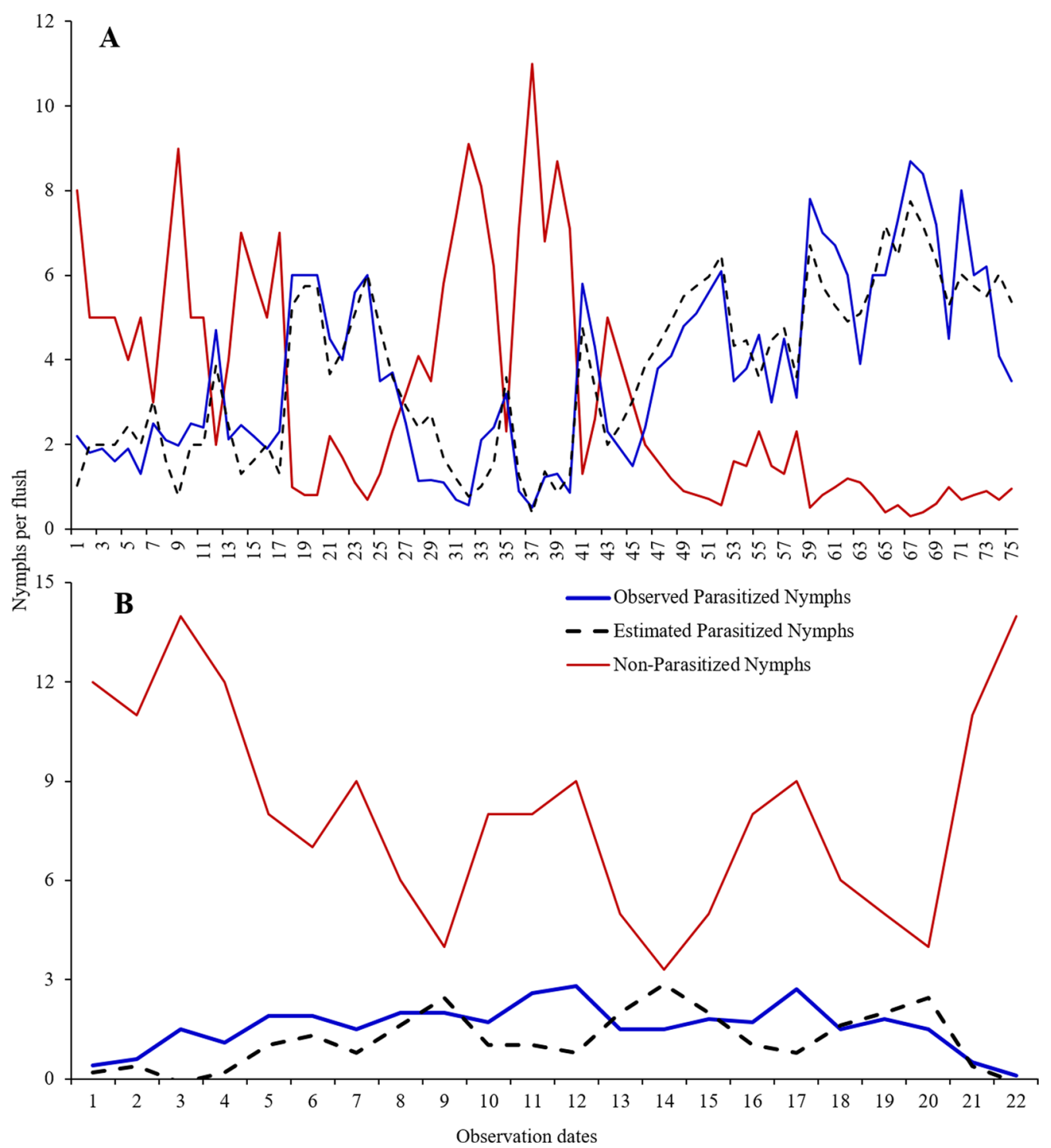

Fig. 4 Nymphs of Diaphorina citri: observed parasitized and non-parasitized, as well as estimated parasitized on: a Murraya paniculata, b Citrus $x$ aurantiifolia

the pest in the rainy periods. Kiritani (2013) reported that, although density-dependent processes regulate the population density of any organism, density-independent processes also influence it, and its magnitude may vary. Studies have shown that rainfall can limit the population development of D. citri (Chavez-Medina et al. 2016). Furthermore, Aubert (1987) reported that monthly rainfall exceeding $150 \mathrm{~mm}$ is generally associated with low populations of $D$. citri due to the washing of eggs and nymphs from the plant surface.

At the end of the rainy season, the population densities of D. citri increased and within the interaction of the plant-psyllid system, another density-dependent process came into play, i.e., the parasitoid, T. radiata. The importance of $T$. radiata as a biocontrol agent of $D$. citri on $M$. paniculata was supported by the high inverse correlation $(r:-0.9119, P<0.05)$ between the number of parasitized and non-parasitized $D$. citri nymphs that resulted in high parasitism rates (Fig. 3a).

The importance of parasitism by $T$. radiata on $D$. citri has been previously established for $M$. paniculata and citrus species. Pluke et al. (2008) observed levels of parasitism, ranged between $70-100$ and $48-70 \%$ for Citrus spp. and M. paniculata, respectively. Releases of $T$. radiata decreased the number of $D$. citri nymphs 


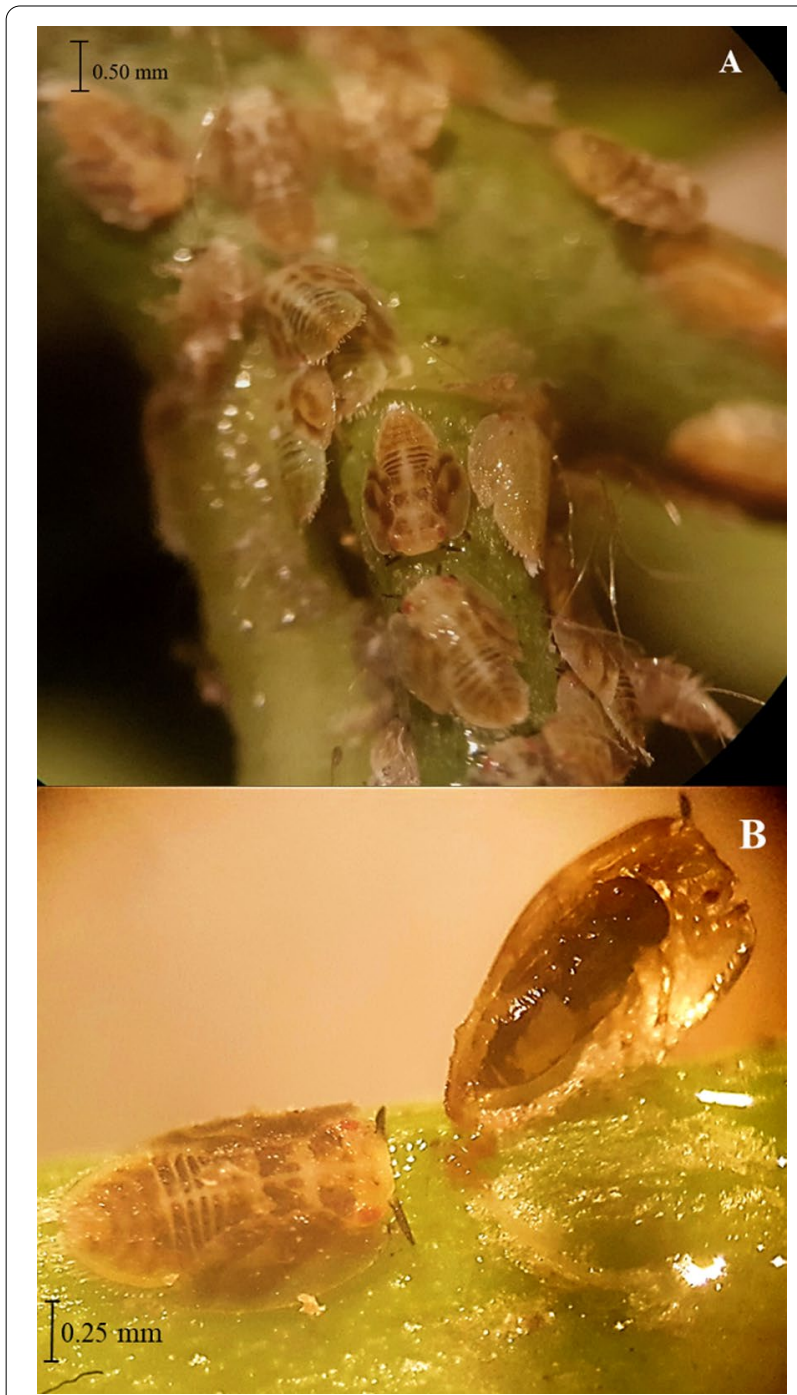

Fig. 5 a Population density of Diaphorina citri nymphs per flush of Citrus x aurantiifolia in the absence of parasitism. Years 2018 and 2019. b Nymphs of Diaphorina citri parasitized by Tamarixia radiata detected on Citrus $x$ aurantiifolia. July 2020 per flush from 42 to 3.8 , which represented (91.2\%) of the population reduction (Flores and Ciomperlik 2017). Four years of study in different regions of Southern California indicated a significant mortality of $D$. citri due to high rates of parasitism by $T$. radiata in citrus plants (Milosavljević et al. 2021).

Parasitism rates of T. radiata on D. citri on M. paniculata and C. x aurantiifolia in Manabí province showed a colonization process of an exotic insect pest and the phenological desynchronization in the colonization of its parasitoid. Thus, the fieldwork showed that M. paniculata was colonized by D. citri in Manabí province approximately in August 2016 (Navarrete et al. 2016) and approximately 2 years later, in May 2018, T. radiata parasitized $D$. citri nymphs were observed (Cuadros et al. 2020).

Subsequently, C. x aurantiifolia, colonized by D. citri at the end of 2018 and this process, together with the absence of parasitism, may explain the high densities detected in that year and especially in the following year (2019). With an asynchrony of 2 years, in July 2020, in this agro-ecosystem, the parasitoid $T$. radiata became part of the interaction with very low rates of parasitism at the beginning, which increased over time.

A similar case of phenological desynchronization (insect host-parasitoid) was reported in Venezuela with the guava cottony scale, Capulinia linarosae Kondo and Gullan, 2016 (Hemiptera: Eriococcidae), a pest of the guava tree, Psidium guajava L. (Myrtaceae). In 1993, this invasive insect species of unknown origin appeared colonizing the guava crop in different guava producing regions of Venezuela (Cermeli and Geraud-Pouey 1997). With a difference of approximately 2 years (January 1996), the wasp parasitoid Metaphycus marensis Chirinos and Kondo, 2019 (Hymenoptera: Encyrtidae) was observed parasitizing C. linarosae on guava (Cermeli and Geraud-Pouey 1997). By 1999, the parasitoid, M. marensis, was fully established and interacting with its host, C. linarosae in the different regions of Venezuela where guava is grown (Geraud-Pouey et al. 2001).

Jeffs and Lewis (2013) reported that time is fundamental for many interspecific interactions that evolve to optimize temporal overlap and additionally mentioned that asynchrony can be part of the adaptive process. The same researchers indicated that few studies have observed the potential for phenological asynchrony between parasitoids and their insect hosts.

The colonization and establishment of D. citri and T. radiata in Manabí province likely occurred first on $M$. paniculata. D. citri was found for the first time on citrus trees and $M$. paniculata $(=M$. exotica) plants in Guayaquil, in the province of Guayas, where the highest population densities (approx. 20 nymphs per flush) were observed on the latter host (Cornejo and Chica 2014). Likewise, the parasitoid T. radiata was also found for the first-time parasitizing D. citri nymphs infesting $M$. paniculata in Guayas province (Portalanza et al. 2017). Thus, it is likely that $D$. citri and $T$. radiata were introduced to the city of Portoviejo, in Manabí province, from the province of Guayas through the retail trade of orange jasmine and other rutaceous plants. A similar situation occurred in Florida, U.S.A., where D. citri dispersed throughout the state through migration of the adult psyllids and the commercial trade of infested M. paniculata plants that were sold as ornamentals (Halbert et al. 2008). 
On the other hand, the citrus growing region of Mejía is located $8 \mathrm{~km}$ from the city of Portoviejo and thus it is likely that the psyllid and its parasitoid were introduced on D. citri infested orange jasmine plants brought from Mejía city, and posteriorly colonized citrus orchards. Thus, the probable pathway, followed by D. citri and T. radiata in Manabí province, is as follows: orange jasmine (Guayas) - orange jasmine (Portoviejo city) orange jasmine (Mejía)-key lime (Mejía).

Despite the short distance between Mejía and Portoviejo cities, the colonization of $C$. $x$ aurantiifolia by the Asian citrus psyllid occurred 2 years later. Parasitization of $T$. radiata on $D$. citri nymphs in orange jasmine in Portoviejo city, probably delayed the colonization of the citrus growing region. The process of colonization and establishment of the plant-psyllidparasitoid interaction observed in $M$. paniculata may be repeated in $C . x$ aurantiifolia. The same pattern in the population dynamics of $D$. citri nymphs occurred on both host plants in terms of the effect of rainfall, the phenological desynchronization between colonization and the establishment of the plant-psyllid-parasitoid interaction. Based on the data gathered on the pattern of colonization of D. citri and T. radiata in M. paniculata, a model for estimating the number of $T$. radiata parasitized $D$. citri nymphs on $M$. paniculata and $C$. $x$ aurantiifolia can be calculated.

Frequency of colonization and establishment events of the Asian citrus psyllid on M. paniculata and C. $\mathrm{x}$ aurantiifolia and subsequent appearance of the parasitoid and its establishment on M. paniculata, may be estimated by the end of 2022, populations of $D$. citri might fluctuate at low levels associated with high percentages of parasitism by $T$. radiata on C. x aurantiifolia. However, in Ecuador, a high percentage of citrus farmers use chemical insecticides to control insect pests (Sornoza-Robles et al. 2020), which would affect the levels of parasitism by $T$. radiata in commercial citrus orchards. Field and laboratory studies have demonstrated the lethal and sublethal effects of pesticides belonging to various chemical groups on $T$. radiata (Beloti et al. 2015). Therefore, it is important to establish biological control and/or integrated pest management programs for the conservation of $T$. radiata and other natural enemies.

\section{Conclusions}

Parasitoids are key regulators in the population fluctuations of their insect hosts. The present study showed the colonization of an invasive citrus pest, $D$. citri and its parasitoid, T. radiata, in a region, first on its ornamental host, M. paniculata and later on key lime, C. x aurantiifolia. The levels of parasitism indicated the importance of $T$. radiata as a biocontrol agent of $D$. citri that could be included in integrated pest management programs as a tool against the eventual arrival of Huanglongbing in Ecuador.

\section{Acknowledgements \\ To Dr. Angel Luis Viloria (IVIC, Venezuela) for kindly reviewing the manuscript and the English text.}

\section{Authors' contributions}

DTC designed the study, DTC, IMC, JV, RC, GS conducted the field sampling and laboratory counts. All authors contributed equally to the analysis and interpretation of the results. DTC, TK wrote the manuscript. All authors read and approved the final manuscript.

\section{Funding}

This research was partially funded by a grant No. PYTEXT524-2019-FIAG0003 "Biology and national inventory of diversity of Diaphorina citri Kuwayama and species of natural enemies in Ecuador".

Availability of data and materials

All data is included in the figures and are so clear.

\section{Declarations}

Ethics approval and consent to participate Not applicable.

\section{Consent for publication}

Not applicable.

\section{Competing interests}

The authors declare that they have no competing interests.

\section{Author details}

${ }^{1}$ Present Address: Facultad de Ingeniería Agronómica, Universidad Técnica de Manabí, Portoviejo, Province of Manabí, Ecuador. ${ }^{2}$ Present Address: Corporación Colombiana de Investigación Agropecuaria - Agrosavia, Palmira Research Station, Palmira, Valle del Cauca, Colombia.

Received: 23 June 2021 Accepted: 20 September 2021

Published online: 27 September 2021

\section{References}

Aubert B (1987) Trioza erytreae Del Guercio and Diaphorina citri Kuwayama (Homoptera: Psylloidea), the two vectors of citrus greening disease: biological aspects and possible control strategies. Fruits 42:149-162

Beloti VH, Alves GR, Araújo DFD, Picoli MM, Moral RA, Demétrio CGB, Yamamoto PT (2015) Lethal and sublethal effects of insecticides used on citrus, on the ectoparasitoid Tamarixia radiata. PLoS ONE 10:e0132128. https:// doi.org/10.1371/journal.pone.0132128

Bové JM (2006) Huanglongbing: a destructive, newly-emerging, century-old disease of citrus. J Plant Pathol 88:7-37. https://doi.org/10.4454/jpp.v88i1. 828

Cañarte-Bermudez E, Navarrete-Cedeño B (2019) Situación fitosanitaria de los cítricos en Ecuador. In: Abstracts of II simposio internacional de producción integrada de frutas. Quito, Ecuador, 24-25 October 2019

Cermeli M, Geraud-Pouey F (1997) Capulinia sp. cercana a jaboticabae von Ihering (Homoptera: Coccoidea: Eriococcidae) nueva plaga del guayabo en Venezuela. Agron Trop 47:115-123

Chavez-Medina JA, Flores-Zamora GL, Góngora-Gómez AM, Gomez RL, GarcíaNegroe CB (2016) Distribución temporal de Diaphorina citri Kuwayama (Hemíptera: Psyllidae) en limón persa (Citrus latifolia Tanaka) en el municipio de Sinaloa, Sinaloa. Entomol Mex 3:324-329

Cornejo JF, Chica EJ (2014) First record of Diaphorina citri (Hemiptera: Psyllidae) in Ecuador infesting urban citrus and orange Jasmine trees. J Insect Sci 14:1-3. https://doi.org/10.1093/jisesa/ieu160 
Cuadros IM, Vélez J, Velasquez J, Chirinos DT (2020) La dispersión del psílido asiático, Diaphorina citri Kuwayama y su parasitoide, Tamarixia radiata (Waterston) en la provincia de Manabí, Ecuador. Investigatio 13:59-64. https://doi.org/10.31095/investigatio.2020.13.6

Erráez M, Mazón M, Troya Armijos H, Valarezo Espinoza D (2020) Identificación y evaluación de la incidencia de insectos y hongos benéficos asociados a Diaphorina citri Kuwayama (Hemiptera: Liviidae) en plantas traspatio (Citrus spp. y Murraya paniculata) del cantón Catamayo (Loja-Ecuador) Ecuad Calid Rev Científica Ecuat 7:25-33. https://doi.org/10.36331/revis ta.v7i1.99

FAOSTAT (2019) Food and agriculture data [WWW Document]. URL http:// www.fao.org/faostat/en/\#data/QC. Accessed 13 May 2021

Flores D, Ciomperlik M (2017) Biological control using the ectoparasitoid, Tamarixia radiata, against the Asian citrus psyllid, Diaphorina citri, in the Lower Rio Grande Valley of Texas. Southwest Entomol 42:49-59. https:// doi.org/10.3958/059.042.0105

Geraud-Pouey F, Chirinos DT, Aguirre R, Bravo Y, Quintero JA (2001) Evaluación de Metaphycus sp. (Hymenoptera: Encyrtidae) como agente de control natural de Capulinia sp. cercana a jaboticabae von Ihering (Hemiptera: Eriococcidae). Entomotropica 16:165-171

Halbert SE, Manjunath KL (2004) Asian citrus psyllids (Sternorrhyncha: Psyllidae) and greening disease of citrus: a literature review and assessment of risk in Florida. Florida Entomol 87:330-353. https://doi.org/10.1653/ 0015-4040(2004)087[0330:ACPSPA]2.0.CO;2

Halbert S E, Manjunath KL, Brodie (2008) Large-scale distribution of Diaphorina citri Kuwayama and citrus huanglongbing MW in Florida. In: Proceedings international. Research conference on Huanglongbing. Plant management network, December 2008, Orlando. URL http://www.plantmanag ementnetwork.org/proceedings/irchlb/2008/presentations/IRCHLB.2.6. pdf. Accessed 12 Jun 2021

Jeffs CT, Lewis OT (2013) Effects of climate warming on host-parasitoid interactions. Ecol Entomol 38:209-218. https://doi.org/10.1111/een.12026

Kiritani K (2013) Different effects of climate change on the population dynamics of insects. Appl Entomol Zool 48:97-104. https://doi.org/10.1007/ s13355-012-0158-y
Miksanek JR, Heimpel GE (2019) A matrix model describing host-parasitoid population dynamics: the case of Aphelinus certus and soybean aphid. PLoS ONE 14:1-20. https://doi.org/10.1371/journal.pone.0218217

Milosavljević I, Morgan DJW, Massie RE, Hoddle MS (2021) Density dependent mortality, climate, and Argentine ants affect population dynamics of an invasive citrus pest, Diaphorina citri, and its specialist parasitoid, Tamarixia radiata, in Southern California, USA. Biol Control. https://doi.org/10. 1016/j.biocontrol.2021.104627

Navarrete J, Cañarte EG, Valarezo GO (2016) First report about the presence of Diaphorina citri (Hemiptera: Liviidae) in Manabi. EspamCiencia 7:141-145

Pluke RWH, Qureshi JA, Stansly PA (2008) Citrus flushing patterns, Diaphorina citri (Hemiptera: Psyllidae) populations and parasitism by Tamarixia radiata (Hymenoptera: Eulophidae) in Puerto Rico. Florida Entomol 91:36-42. https://doi.org/10.1653/0015-4040(2008)091 [0036:CFPDCH] 2.0.CO;2

Portalanza DE, Sanchez L, Plúas M, Felix I, Costa VA, Dias-Pini NS, FerreiraStafanous S, Gómez-Torres ML (2017) First records of parasitoids attacking the Asian citrus psyllid in Ecuador. Rev Bras Entomol 61:107-110. https:// doi.org/10.1016/j.rbe.2017.02.002

Sornoza-Robles D, Zambrano-Gavilanes FE, Moreira-Saltos JR, ZambranoDueñas JF, Armiñana-García R, Fimia-Duarte R (2020) Farmers' perception of the efficacy of parasitoids in pest control and agroecological sustainability of Limonero, Riochico, Portoviejo, Ecuador. Neotrop Helminthol 14:75-84. https://doi.org/10.24039/rnh2020141629

Teck SLC, Fatimah A, Beattie A, Heng RKJ, King WS (2011) Influence of host plant species and flush growth stage on the asian citrus psyllid, Diaphorina citri Kuwayama. Am J Agric Biol Sci 6:536-543. https://doi.org/10. 3844/ajabssp.2011.536.543

\section{Publisher's Note}

Springer Nature remains neutral with regard to jurisdictional claims in published maps and institutional affiliations.

\section{Submit your manuscript to a SpringerOpen ${ }^{\circ}$ journal and benefit from:}

- Convenient online submission

- Rigorous peer review

- Open access: articles freely available online

- High visibility within the field

- Retaining the copyright to your article

Submit your next manuscript at $\boldsymbol{\nabla}$ springeropen.com 